\title{
Relato de experiência da atuação do nutricionista em Residência Multiprofissional em Saúde
}

\author{
Experience report of dietitians \\ working in multidisciplinary \\ health residency
}

\author{
Claudia Cristina ALVES ${ }^{1,2}$ \\ Maria Carolina NETTO2 \\ Ana Paula Geraldo de SOUSA² \\ Macarena Urrestarazu DEVINCENZ12,3
}

\section{R E S U M O}

Residências Multiprofissionais em Saúde constituem uma estratégia de formação de recursos humanos para o Sistema Único de Saúde. Ainda que sejam implementadas as necessárias mudanças curriculares nas graduações em saúde, há que se considerar essa modalidade como uma oportunidade de educação permanente. O presente artigo propõe apresentar um relato de experiência da atuação de nutricionistas em um Programa de Residência Multiprofissional em Saúde, enfatizando as potencialidades e os desafios de um fazer coletivo em equipe multiprofissional tanto no âmbito da atenção primária quanto no da atenção terciária à saúde, nas linhas de cuidado do adulto e do idoso, da mulher e do recém-nascido, da criança e na saúde mental. A elevada carga horária, a diversidade de cenários e a complexidade das situações vivenciadas na Residência preparam o profissional para os desafios de sua futura atuação no Sistema Único de Saúde.

Palavras-chave: Educação de pós-graduação. Nutrição. Recursos humanos. Sistema Único de Saúde.

\section{A B S T R A C T}

Multidisciplinary health residencies constitute a human resource training strategy for the Unified Health Care System. Even if the necessary curricular changes are implemented in health undergraduate programs, this modality has to be considered an opportunity for ongoing education. The present article proposes to present

\footnotetext{
${ }^{1}$ Universidade Federal de São Paulo, Curso de Nutrição, Departamento de Biociências. R. Silva Jardim, 136, Campus Baixada Santista, 11015-020, Santos, SP, Brasil. Correspondência para/Correspondence to: CC ALVES. E-mail: <claudiacalves@gmail.com>.

${ }^{2}$ Universidade Federal de São Paulo, Programa de Residência Multiprofissional em Atenção à Saúde. Santos, SP, Brasil.

${ }^{3}$ Universidade Federal de São Paulo, Curso de Nutrição, Departamento de Gestão e Cuidados em Saúde. Santos, SP, Brasil.
} 
a dietitians' report of their experience working in a multidisciplinary health residency program, emphasizing the potentialities and challenges of collective work in a multidisciplinary team, both in primary and tertiary health cares, in caring for adults, older adults, women, newborns, children, and individuals with mental health problems. The high working time, scenario diversity, and complexity of the situations seen during the residency prepare the professional for their future work at the Unified Health Care System.

Keywords: Education, graduate. Nutrition. Human resources. Unified Health System.

\section{N T R O D U Ç Ã O}

Frente à nova configuração da atenção à saúde e atuação em equipe, o Sistema Único de Saúde (SUS), responsável pela qualificação dos recursos humanos, desenvolveu, através do Ministério da Saúde e do Ministério da Educação, os programas de Residência Multiprofissional e em área Profissional em Saúde. As Residências visam a formação de recursos humanos qualificados para a reorganização assistencial da saúde proposta pelo SUS'.

O Ministério da Saúde vem apoiando Residências Multiprofissionais em Saúde desde 2002. O estabelecimento de financiamento regular para esse tipo de programa no Brasil e o investimento na sua potencialidade pedagógica e política tem por objetivo possibilitar tanto a formação de profissionais quanto contribuir com a mudança do desenho tecnoassistencial do SUS?

Os Programas de Residência Multiprofissional em Saúde constituem uma pós- graduação lato sensu oferecida às categorias profissionais que se relacionam com a saúde, com exceção da médica, caracterizada essencialmente por educação em serviço. Trata-se de uma formação que acontece em dedicação exclusiva, com carga horária total de 5760 horas, sendo que 4608 horas são práticas (80\%) e 1 152, teóricas ou teórico-práticas $(20 \%)^{2,3}$.

A intrínseca característica da interdisciplinaridade confere caráter inovador aos programas de Residência Multiprofissional em Saúde, visando a formação coletiva inserida no mesmo campo de trabalho sem, no entanto, deixar de priorizar e respeitar os núcleos específicos de saberes de cada profissão. Os diversos lugares os quais construíram esses programas, o fizeram procurando aproximar o ensino da gestão em saúde, o que por si só já constitui inegável inovação na formulação de políticas para formação de trabalhadores do e para o SUS'.

No processo de formação do residente, a população, o controle social, a equipe da unidade, as escolas do bairro, enfim, todos os envolvidos são convidados a pensar e a produzir espaços de saúde e qualidade de vida. Essas experiências demonstram o quão produtivos os lugares podem se tornar quando devidamente estimulados. São histórias de pessoas que pensam o cuidado como algo complexo e possível de ser realizado com integralidade, que demonstram como se tem trabalhado de forma dinâmica na prática dos serviços para promover a solução dos problemas de saúde de forma transdisciplinar e intersetorial, atentando às questões socioeconômicas, culturais, ecológicas e religiosas ${ }^{1}$.

Atualmente, sabe-se que a abordagem alimentar e nutricional ganha relevância e está associada à melhoria do perfil epidemiológico da população, levando a diminuição dos gastos com saúde pelo Estado. Isso indica a notória necessidade de ampliar a formação para o cuidado alimentar e nutricional da população. Nesse sentido, Santos et al. ${ }^{4}$ verificaram que a experiência de inserção do nutricionista por meio da Residência Multiprofissional em Saúde da Família oportunizou vivências práticas, ampliando conhecimentos, habilidades e atitudes suficientes para atuar na diversidade das demandas sociais, econômicas, políticas e educativas no contexto das comunidades e do SUS.

Entende-se, assim, a necessidade de produção de conhecimento e divulgação das experiências na área, visto que esse novo modelo de 
fazer em saúde vem se consolidando gradativamente. Considera-se, ainda, a potencialidade da Residência Multiprofissional em Saúde para romper com os paradigmas existentes em relação à formação de profissionais para o SUS, bem como em contribuir para qualificar a atenção que os serviços de saúde locais necessitam ofertar às suas comunidades. Essa necessidade tem sido apontada recentemente na área de nutrição em estudo desenvolvido por Aguiar \& Costa $^{5}$ com nutricionistas de Núcleos de Apoio à Saúde da Família do estado de Goiás. Os profissionais manifestaram que sua formação acadêmica não as preparou para esse tipo de atuação. Entretanto, ainda que sejam implementadas as necessárias mudanças curriculares nas graduações em saúde, há que se considerar a Residência em Saúde como uma oportunidade de formação continuada.

Dessa forma, o presente artigo propõe apresentar um relato de experiência da atuação de nutricionistas em um Programa de Residência Multiprofissional em Saúde. A partir disso, busca enfatizar as potencialidades e os desafios de um fazer coletivo em equipe multiprofissional tanto no âmbito da atenção primária quanto no da atenção terciária à saúde.

\section{Residência Multiprofissional em Atenção à Saúde}

Com a finalidade de formar um profissional de saúde capaz de colocar o saber específico na direção de um saber compartilhado e que, não abrindo mão da sua formação, possa estar atento às diferenças, aos movimentos de inclusão e ao interprofissionalismo em todos os níveis de atenção à saúde junto a indivíduos, famílias e redes sociais, a Universidade Federal de São Paulo, Campus Baixada Santista (Unifesp), implantou, em 2010, o Programa de Residência Multiprofissional em Atenção à Saúde. Esse programa assumiu como eixo transversal a "Atenção à saúde do indivíduo, família e sua rede social" e oito eixos perpendiculares (áreas profissionais). Tanto o eixo transversal quanto os perpendiculares desenvolvem-se na atenção primária e terciária em saúde nas seguintes linhas de cuidado: saúde do adulto e do idoso; saúde da mulher e do recém-nascido; saúde da criança e do adolescente; e saúde mental ${ }^{6}$.

O Programa firmou parceria com o Hospital Irmandade da Santa Casa da Misericórdia de Santos e com a Secretaria Municipal de Saúde da cidade. Ambos viabilizaram cenários de prática aos residentes e funcionários como preceptores, constituindo pilares imprescindíveis da proposta de preparo de profissionais de saúde para o trabalho em equipe na perspectiva da integralidade no cuidado e da contínua relação com as políticas de saúde locorregionais, interligando o ensino e o serviço ${ }^{6}$.

A carga horária semanal de 60 horas foi dividida ao longo da semana, sendo que de segunda a quinta-feira aconteciam as atividades práticas nos cenários de atuação e, na sexta-feira, as atividades teóricas na Unifesp, ambas das $7 \mathrm{~h}$ às 19h. Com relação a estas últimas, as mesmas eram divididas em discussões de casos, aulas multiprofissionais e encontros mensais com tutores específicos de cada profissão.

No programa, em uma atividade de extensão da Unifesp, Campus Baixada Santista, participavam tutores e docentes os quais acompanhavam os aspectos acadêmicos da formação, bem como realizavam supervisões nos cenários de serviço. Segundo a Resolução $n^{\circ} 2$ de 13 de abril de 2012 da Comissão Nacional de Residência Multiprofissional em Saúde, a função de tutor caracteriza-se por atividade de orientação acadêmica de preceptores e residentes, estruturada preferencialmente nas modalidades de tutoria de núcleo e tutoria de campo. A tutoria de núcleo corresponde à atividade de orientação acadêmica voltada à discussão das atividades teóricas, teórico-práticas e práticas do núcleo específico profissional; já a tutoria de campo corresponde à atividade de orientação acadêmica voltada para a discussão das atividades teóricas, teórico-práticas e práticas desenvolvidas pelos preceptores e residentes no âmbito do campo de conhecimento, 
integrando os núcleos de saberes e práticas das diferentes profissões que compõem a área de concentração do programa, nesse caso, a saúde coletiva.

Dessa forma, os tutores de campo dedicavam quatro horas, ou seja, um período na semana, para a supervisão das práticas nos serviços junto à equipe multiprofissional de residentes e preceptores, sendo que havia tutores da atenção básica e da área hospitalar. Os tutores de núcleo eram os responsáveis pelos encontros específicos com os residentes de cada área profissional, os quais aconteciam uma vez por semana, também com duração de quatro horas, para discussão teórica específica.

A multiprofissionalidade desenvolvida nesse programa de Residência articulava as áreas de Educação Física (a partir de 2012), Enfermagem, Fisioterapia, Nutrição, Psicologia, Serviço Social e Terapia Ocupacional. Anualmente, ofertavam-se 14 vagas, distribuídas nas sete profissões, sendo que, para a prática nos cenários, os residentes eram agrupados em duas equipes multiprofissionais com um representante de cada área. Entre os anos de 2010 e 2012, foram oferecidas vagas para a área de Farmácia, sendo excluída a partir de 2013.

O programa partia dos princípios e diretrizes do SUS, buscando promover uma visão ampliada do processo saúde-doença que convergisse com uma atuação ética e integral. Tudo isso sem negligenciar a premissa da multiprofissionalidade e da interdisciplinaridade, mantendo o foco tanto na atenção terciária quanto na atenção primária à saúde.

No intuito de vivenciar a experiência de integralidade da atenção à saúde, havia um período de estágio no nível primário e um no terciário. Nesses períodos, os residentes podiam organizar e discutir a referência e a contrarreferência de casos na rede de saúde. Assim, o campo de prática na atenção primária ocorria em Unidades Básicas de Saúde (UBS) (ao longo dos anos, equipes de residentes atuaram nas diferentes regiões da cidade: Centro, Morros, Zona Noroeste e Orla). Importante destacar que as UBS indicadas pela Secretaria Municipal de Saúde de Santos para serem cenários das atividades práticas do Programa de Residência funcionavam até as $21 \mathrm{~h}$, sendo possível, portanto, cumprir a carga horária diária necessária. Já a atenção terciária ocorria na Irmandade da Santa Casa da Misericórdia de Santos, sendo este o Hospital de referência para a Baixada Santista e região do Vale do Ribeira.

No primeiro mês do Programa, havia um período de integração e aulas teóricas multiprofissionais na Unifesp, apresentando temas relacionados ao SUS, território, trabalho em equipe, visitas domiciliárias, estratégias de grupos, projetos terapêuticos singulares, entre outros. Essa integração tinha como finalidade que os residentes se conhecessem, além de envolver os tutores e preceptores do programa em diferentes momentos, visando uma aproximação inicial. Após esse período, era realizado um sorteio entre os 14 profissionais para dividi-los em duas equipes (uma para cada cenário de atuação) e, depois de 10 meses de atuação, ocorria a troca de equipes nos cenários. Eram promovidos encontros mensais com as duas equipes chamados de "reuniões de integralidade", visando discutir casos e construir linhas de cuidado e visão de rede.

A troca de cenário acontecia em um período chamado de "transição", onde os residentes de cada cenário apresentavam o ambiente, equipes do serviço, atividades e propostas de trabalho realizadas àqueles que lá iniciariam suas atividades. A "transição" durava, aproximadamente, uma semana no ambiente hospitalar e duas na UBS.

\section{Estratégias de atuação na Atenção Básica}

A política nacional de atenção básica mais recente caracteriza-se por um conjunto de ações, no âmbito individual e coletivo, que abrange a promoção, a proteção e a manutenção da saúde, a prevenção de agravos, o diagnóstico, o tratamento, a reabilitação e a redução de danos com 
o objetivo de desenvolver uma atenção integral que impacte na situação de saúde e autonomia das pessoas e nos determinantes e condicionantes dessa situação nas coletividades. Para tanto, prevê a utilização de tecnologias de cuidado complexas e variadas as quais devem auxiliar no manejo das demandas e necessidades de saúde de maior frequência e relevância no território, observando critérios de risco, vulnerabilidade, resiliência e o imperativo ético de que toda demanda, necessidade de saúde ou sofrimento devem ser acolhidos $^{7}$. Nesse aspecto, a proposta dos programas de Residência, além da formação de profissionais recém graduados, é de ser uma política indutora para educação permanente dos trabalhadores do SUS, os quais atuam como preceptores. Estes podem, a partir do encontro com os residentes, rever seus processos de trabalho ${ }^{8}$.

Nesse sentido, a proposta de atuação e vivência dos residentes nesse Programa de Residência Multiprofissional em Atenção à Saúde da Universidade Federal de São Paulo, Campus Baixada Santista (Unifesp), baseou-se, inicialmente, na atuação em UBS localizadas em bairros com altos índices de violência, prostituição, uso e tráfico de drogas e vulnerabilidade social. Inicialmente houve certa apreensão por parte dos residentes, porém após a inserção, foram desenvolvidas formas de lidar com o contexto, como, por exemplo, deixar o local, sempre que possível, na companhia dos agentes comunitários de saúde, com identificação ou uso de jalecos, sempre em duplas ou com mais membros da equipe; além disso, foi incentivada a criação de vínculos com os moradores e locais estratégicos da região, como comércios e outros serviços.

Outra dificuldade foi atuar 12 horas por dia em um serviço onde não existem, diariamente, funcionários de todas as categorias profissionais da equipe multiprofissional da residência. Somente médicos, enfermeiros, técnicos de enfermagem e agentes comunitários de saúde trabalham todos os dias nas unidades onde aconteciam as atividades. Em dias específicos da semana, há o atendimento da assistência social, da nutrição e da psicologia. Outros profissionais, como o fisioterapeuta e o terapeuta ocupacional, estão inseridos apenas em outros serviços, na atenção secundária, como no Ambulatório de Especialidades e na Seção de Reabilitação e Fisioterapia, por exemplo.

A necessidade de organizar a equipe de residentes para dar início aos trabalhos foi o maior de todos os desafios, afinal as mesmas eram formadas por pessoas diferentes, vindas de locais e formações distintos. Além disso, existia a necessidade de comunicação com os profissionais da própria unidade básica, visando esclarecer a proposta de inserção e atuação dos residentes em seu ambiente de trabalho. Muitos desentendimentos aconteceram, porém, foram trabalhados de maneira adequada, sem afetar ou prejudicar a população atendida.

Em um primeiro momento, o grupo de residentes passou por um período de observação para que as intervenções fossem baseadas nas necessidades da população atendida. Nesse sentido, foram trabalhados os pressupostos da multiprofissionalidade através de dinâmicas em grupo, atividades educativas, salas de espera, sensibilização da equipe e dos usuários, abarcando a comunidade e os profissionais de saúde.

A experiência do nutricionista enquanto residente na atenção básica fez com que repensasse a prática dos profissionais da área de saúde, a qual deve abranger não apenas o atendimento individual, mas buscar formas de atender o coletivo. A partir disso, foram proporcionadas trocas de experiências com a comunidade e outros profissionais através da elaboração de projetos multiprofissionais, isso porque a demanda de um indivíduo certamente vai além do aspecto nutricional. O projeto multiprofissional, baseado no conceito da clínica ampliada e compartilhada, foi organizado para cada linha de cuidado por meio da interação entre os vários conhecimentos técnicos específicos, almejando a produção de uma solução/proposta de intervenção a qual não poderia ser alcançada pelos profissionais isoladamente ${ }^{8}$.

Para o atendimento nutricional, as formas de intervenção mais utilizadas foram as atividades 
em grupo, aproximando os profissionais dos usuários e valendo-se de atendimentos individuais, quando necessário. Apesar de terem sido desenvolvidas atividades nas diferentes linhas de cuidado, a nutrição esteve mais presente na área materno-infantil. A atuação aconteceu em dois grupos, um de aleitamento materno e outro de gestantes, afetivamente denominado "Unidos por cordão e coração".

Na chegada à Unidade Básica de Saúde, identificou-se, durante o período de observação, a ausência de atividades coletivas destinadas ao período gestacional, sendo este um dos motivos que levou ao direcionamento de maior atenção a esse público. O grupo foi desenvolvido semanalmente em dois horários, antes das consultas com os ginecologistas. No início, houve dificuldades para constituí-lo, mas essa não era uma realidade apenas do grupo de gestantes, vários outros enfrentam dificuldades até estarem totalmente estruturados e obterem adesão satisfatória. Embora o início tenha sido conturbado e desafiador, não houve desistência por parte dos residentes e, assim, as propostas de trabalho continuaram. Depois das primeiras semanas, era marcante a presença contínua de algumas munícipes o que tornou possível, enfim, a consolidação das atividades com o grupo que, a cada dia, era prestigiado com mais participantes e com o interesse e envolvimento das gestantes.

Vários grupos aconteceram e muitas demandas foram levantadas. Foram abordados temas, como: preparo das mamas; amamentação; relação com os filhos mais novos; tabagismo; tipos de parto; direito das mulheres; alterações corporais na gestação; cuidados com o recém-nascido; suplementação nutricional: a importância do sulfato ferroso e do ácido fólico; musculatura do assoalho pélvico; saúde bucal; alimentação na gestação; puerpério e lactação; mitos e verdades; sexo na gestação; fases do desenvolvimento fetal; e, por fim, a importância das vacinas no período gestacional. A cada semana, a equipe de residentes planejava e estruturava um novo tema a ser debatido. Havia o desejo e o esforço em sanar dúvidas e demandas individuais das gestantes, mas nem sempre era possível responder às questões durante os encontros. Dessa forma, algumas aproximações individuais foram requisitadas e acompanhadas, o que ampliou ainda mais a possibilidade de conhecer e contribuir com essa fase da gestação.

Em vista da devolutiva positiva recebida das participantes, verificada por meio da frequência constante nos encontros e da procura espontânea pelos profissionais residentes na UBS tanto nos grupos quanto nos acompanhamentos individuais, acredita-se que foi possível compreender as alterações provocadas na vida das gestantes e tentar encontrar conjuntamente caminhos para que pudessem prosseguir da melhor maneira, entendendo as dificuldades desse período e reconhecendo aspectos positivos na gravidez, tornando a ansiedade um sentimento positivo até o nascimento do bebê.

Os residentes foram em muito contaminados pela ansiedade em conhecer a criança acompanhada durante a fase gestacional, sendo esta amenizada quando, muitas vezes, as mães traziam seus bebês para a consulta com a pediatra ou para o grupo de aleitamento materno. Ressalta-se, assim, a importância de dar continuidade ao atendimento para que as dúvidas sejam esclarecidas e para que as gestantes e puérperas continuem encontrando espaços de acolhimento.

O grupo de aleitamento materno acontecia às $12 \mathrm{~h}$ nas segundas-feiras, antes da consulta com o pediatra. O grupo já existia na unidade e era conduzido pela pediatra, que foi muito receptiva e corresponsabilizou os residentes pela condução do mesmo. Os trabalhos foram iniciados sob livre demanda, sem temas pré-determinados, com abordagens em aleitamento, nutrição da mãe e do bebê, vínculo entre o bebê e outros familiares (pai, irmãos etc.), desenvolvimento neuropsicomotor, estimulação precoce e cuidados com o recém-nascido.

A estimulação do bebê, por exemplo, foi um tema bastante discutido, tendo sido apresentadas as etapas do desenvolvimento da criança e 
orientações sobre estimulação a partir da construção de um espaço livre e seguro para a criança explorar, além de esclarecidas dúvidas com relação ao uso de andadores e a permanência da criança no carrinho por longos períodos. Vale frisar, ainda, que houve a participação de familiares e companheiros das lactantes em alguns grupos, os quais se interessavam pelas informações discutidas e também apontavam questionamentos. A participação destes no processo de aleitamento materno, estimulação e desenvolvimento do bebê é essencial para compreender a importância em dividir tarefas com a puérpera, não apenas orientando, mas, principalmente, dando apoio e atenção, essencial no período de amamentação.

Durante esse processo, o aleitamento materno exclusivo até os seis meses de idade foi extensamente discutido e preconizado. A manutenção do aleitamento até os dois anos de idade ou mais foi igualmente incentivado. Nesse período, as participantes traziam dúvidas, trocavam experiências e construíam uma identidade dentro do grupo. Muitas vezes, as mulheres eram observadas compartilhando informações aprendidas durante os encontros.

Algumas participantes relatavam dificuldades na amamentação devido a feridas e rachaduras nos mamilos e, por meio de conversas, verificava-se que a mamada da criança estava quase sempre inadequada, favorecendo as intercorrências. Além disso, muitas mães recorriam ao uso de pomadas sem orientação médica, o que prejudicava ainda mais o processo de aleitamento, pois, entre outras consequências, esses produtos alteram o gosto do leite, contribuindo com a recusa por parte do recém-nascido. Algumas das participantes, que já haviam vivenciado situação semelhante, repassavam as orientações já adquiridas em grupos anteriores, como, por exemplo, passar o próprio leite do peito nos mamilos e/ou aréola.

Desde o início da abordagem, houve o cuidado em não culpabilizar as puérperas, caso não amamentassem exclusivamente. Foram orientadas, no entanto, com relação à importância do aleitamento, sendo acolhidas e valorizadas em seu conhecimento, bem como recebendo suporte para o enfrentamento das dificuldades encontradas no processo de amamentação.

Ao final do período de atuação da residência na UBS, observou-se que foram atingidos os objetivos propostos para esse grupo específico, no que diz respeito à importância do acompanhamento gestacional, puerperal e do recém-nascido. As ações entraram em congruência com as políticas de incentivo ao aleitamento materno exclusivo do Ministério da Saúde e, por meio delas, buscou-se chegar mais próximo do usuário e de seu cuidado integral ao longo da trajetória.

Além da linha de cuidado materno-infantil também foram desenvolvidas atividades com a saúde do adulto e do idoso através de atendimentos individuais e em grupos. Já existiam grupos conduzidos pelos profissionais da unidade básica em questão, um com pacientes insulinodependentes e outro visando a estimulação à prática de exercícios físicos. A participação da equipe multiprofissional de residentes permitiu diversificar a dinâmica e os temas dos grupos.

O grupo de pacientes insulinodependentes (tanto de diabetes mellitus 1 quanto da 2) foi desenvolvido nos dias de entrega de insumos e medicamentos, facilitando a participação da comunidade. A nutrição participou diversas vezes, abordando temas como alimentação saudável e índice glicêmico dos alimentos. Foram esclarecidas muitas dúvidas, especialmente sobre o consumo de frutas, uma vez que era comum sua restrição por parte dos munícipes devido a orientações recebidas de outros profissionais.

No grupo de exercícios físicos, a nutrição foi abordada com o tema importância da hidratação e, em outro momento, foi realizada uma dinâmica para esclarecer dúvidas, sobre diversos assuntos que envolviam alimentação, daqueles que permaneciam na sala de espera da UBS.

Uma questão fundamental durante todo o processo de trabalho foi o contato com a realidade social das famílias, observado através de 
visitas domiciliares que, para muitos residentes, era algo novo, nunca antes vivenciado. Foram observados e atendidos munícipes em situação de rua, moradores de cortiços em precárias condições higiênico-sanitárias, mães com uma média de sete filhos alimentados com um único pacote de macarrão instantâneo, além de mulheres que se prostituíam para alimentar a família, entre outras. Todas essas vivências ajudaram a refletir e amadurecer tanto profissionalmente quanto pessoalmente.

Para atuar em cenário de tamanha complexidade, a Residência permitiu compor com as estratégias adotadas pela equipe de saúde da UBS, especialmente com os agentes comunitários de saúde no contato com a comunidade. Também aconteceu a participação em reuniões do território, envolvendo profissionais de outros setores, como a assistência social e a educação, e em reuniões do conselho local de saúde. Além disso, a vivência de trabalho da própria equipe multiprofissional de residentes, especialmente com as áreas de terapia ocupacional, psicologia e serviço social, ampliou as competências e estratégias de cuidado em saúde na comunidade.

\section{Desafios de atuação no ambiente hospitalar}

As atividades da Residência Multiprofissional em Atenção à Saúde inseridas no ambiente hospitalar da Irmandade da Santa Casa de Misericórdia de Santos ocorreram nas enfermarias que contemplam as linhas de cuidado: saúde do adulto e do idoso; da mulher e do recém-nascido; e da criança. Esse hospital é uma instituição filantrópica, bem como um hospital auxiliar de ensino, atendendo tanto pacientes do SUS quanto da saúde suplementar. Entretanto, como o programa de Residência em questão era uma iniciativa para a formação de profissionais para o SUS, assistia exclusivamente os pacientes dele oriundos.

Após um período de adaptação com o intuito de vivenciar a dinâmica de funcionamento de cada unidade de internação, a equipe de residentes elaborava um plano de ações de acordo com as especificidades da enfermaria e atuava por cerca de dois meses em cada uma das linhas de cuidado. Embora os residentes multiprofissionais atuassem nas unidades de internação, não eram responsáveis pelos pacientes nelas atendidos; essa responsabilidade era do preceptor de cada área ou de outro profissional do serviço (preceptor de campo).

Como havia somente uma equipe de residentes multiprofissionais, não foi possível atender todos os pacientes de cada unidade de internação. Dessa forma, foram estabelecidos critérios para selecionar e acompanhar os pacientes de acordo com as características de cada unidade de internação e considerando a proposta de intervenções voltadas à integralidade. Todos os pacientes atendidos pela equipe de residentes tinham uma dupla ou trio de profissionais de referência a fim de estabelecer um contato mais próximo no período de internação e a melhor condução das propostas de intervenção.

Após a seleção do caso, o atendimento tinha início com o acolhimento do paciente e/ou familiares por uma dupla de residentes, com a finalidade de conhecer o histórico de vida e processo saúde-doença para identificação das necessidades. Após entrevista e coleta de informações sobre o paciente e familiares, cada caso era discutido por toda a equipe de residentes, juntamente com alguns dos preceptores, em uma reunião diária, para que todos pudessem sugerir intervenções e participar da construção do Projeto Terapêutico Singular (PTS).

O PTS é um conjunto de propostas e condutas terapêuticas articuladas para um indivíduo ou grupo, que objetivarão ampliar o cuidado em saúde. É um instrumento o qual ultrapassa o paradigma médico centrado, buscando a resolução das necessidades das pessoas para além do critério diagnóstico ${ }^{9}$. A construção do PTS é feita nas reuniões das equipes de saúde com apoio matricial, se necessário, sendo este uma retaguarda especializada para equipes e profissionais encar- 
regados da atenção à saúde. O apoio matricial é uma metodologia de trabalho complementar a qual utiliza mecanismos de referência e contrarreferência, protocolos e centros de regulação. Ele se dá através da assistência direta aos usuários ou do suporte técnico-pedagógico às equipes de saúde ${ }^{10}$.

Para a construção do PTS, ou seja, para a elaboração de um plano de cuidado individual ou coletivo, foram considerados os acometimentos físicos e emocionais; as formas de organização do cuidado pelo indivíduo e/ou família; a composição e dinâmica familiar; a relação paciente/cuidador; a relação paciente/profissionais de saúde; e o processo de hospitalização. Tudo isso buscando abordar os aspectos relacionados à saúde a partir do ponto de vista biopsicossocial. A partir do PTS, além da intervenção hospitalar, a equipe articulava a alta com os serviços de assistência, educação e saúde necessários para a continuidade do cuidado no território, por meio de contatos telefônicos e do envio de relatórios de contrarreferências.

Para melhor organização e comunicação entre os profissionais da instituição e a equipe de residentes, foram elaboradas escalas para acompanhamento da passagem do plantão da enfermagem. Esse procedimento teve o intuito de conhecer as admissões da enfermaria e identificar os pacientes que atendiam aos critérios de seleção, além de obter mais informações para as discussões dos casos já atendidos pela equipe de residentes.

Foram realizadas intervenções em grupos com pacientes e seus acompanhantes, oficinas de brinquedos, ações pontuais focando a saúde do trabalhador com os funcionários da unidade de internação, entre outras. Todo o planejamento e execução das ações eram discutidos entre a equipe de residentes e os preceptores. As intervenções foram planejadas de acordo com o tipo de unidade de internação e público-alvo. Buscou-se, com pouco êxito, a inserção nas discussões da residência médica e outras categorias profissionais de forma a contribuir com a prática multiprofissional.
Houve a constante busca de informações, esclarecimento de dúvidas e realização de trabalho compartilhado com os profissionais da unidade de internação. No entanto, como a instituição era um hospital de ensino, existia uma alta rotatividade de residentes e internos da medicina, estagiários da graduação e nível técnico de diferentes áreas da saúde, dificultando a integração nas unidades de internação.

\section{Saúde do adulto e do idoso}

A enfermaria que contemplou essa linha de cuidado era composta por pacientes do gênero masculino das vagas da Rede de Urgência e Emergência (RUE) e por pacientes da neurocirurgia de ambos os gêneros oriundos do SUS. A Rede de Atenção às Urgências prioriza as linhas de cuidado cardiovascular, cerebrovascular e traumatológica. A organização da RUE tem a finalidade de articular e integrar todos os serviços de saúde, objetivando ampliar e qualificar o acesso humanizado e integral aos usuários em situação de urgência/ emergência nos serviços de saúde de forma ágil e oportuna. As vagas são articuladas pela referência da região e a secretaria que as coordenam é responsável pela administração e encaminhamento dos pacientes aos referidos leitos ${ }^{11}$.

Com recursos regulados a partir da Portaria $n^{\circ} 1.267$, de 20 de junho de 2012, sobre o Plano de Ação da Rede de Atenção às Urgências do Estado de São Paulo'2, o hospital Santa Casa de Santos está inserido na RUE e conta com 60 leitos de enfermaria e 30 de UTI. As prioridades dos leitos RUE na instituição são cardiovascular, cerebrovascular e traumatológica, trabalhadas a partir de suas respectivas linhas de cuidado.

A seleção de pacientes para o atendimento pela equipe de residentes seguiu um ou mais dos seguintes critérios: maiores de 18 anos; indicação pelos profissionais da unidade de internação; demandas identificadas nos atendimentos das áreas específicas; e pacientes pertencentes ao território abrangente da UBS onde estava a outra equipe de residentes. 
No contexto da nutrição, além da contribuição específica nos diferentes pacientes selecionados pela equipe de residentes, a atuação ocorreu com a realização da rotina já estabelecida pelo serviço da unidade de internação. As atividades foram supervisionadas pela nutricionista responsável pela enfermaria, a qual também era preceptora do Programa de Residência. Foram realizadas visitas diárias à beira do leito para adaptação da dieta conforme as doenças, sintomas, intolerâncias e preferências alimentares dos pacientes; orientação de dieta na alta hospitalar; e discussão dos casos com os profissionais da unidade (incluindo a equipe médica da Nutrologia). Também eram realizadas avaliações nutricionais dos pacientes em uso de terapia nutricional oral, enteral ou parenteral e também daqueles sob risco nutricional ou com quadro de desnutrição.

\section{Saúde da mulher e recém-nascido}

As atividades da equipe de residentes na linha de cuidado de saúde da mulher e recém-nascido foram realizadas com atendimentos às gestantes internadas com alguma patologia obstétrica e às puérperas, acompanhadas de seus recém-nascidos. As pacientes selecionadas para o atendimento pela equipe de residentes eram usuárias do SUS (pois, nessa enfermaria, também havia pacientes atendidas na saúde suplementar), primigestas/primíparas com até 16 anos, gestantes com patologias obstétricas, puérperas com antecedentes pessoais de patologias (hipertensão arterial, diabetes, dentre outras), puérperas com idade maior ou igual a 40 anos, pacientes indicados pelos profissionais da maternidade e pacientes pertencentes ao território abrangente da UBS da região do Centro, local onde a outra equipe de residentes estava atuando.

As ações dos residentes nessa unidade de internação se concretizaram por meio dos atendimentos individualizados ou compartilhados, seguidos da discussão dos casos com os profissionais da unidade. Buscou-se estabelecer articulação com a rede de cuidados.
A equipe multiprofissional realizou intervenções desde a admissão da paciente até o acompanhamento no momento do parto, sendo elas: o acolhimento da parturiente, a comunicação entre ela e seus familiares, esclarecimentos sobre a assistência ao parto, bem como condutas voltadas ao alívio da dor e preparo do parto feitas pela fisioterapeuta e pela enfermeira da equipe. Foram realizadas atividades em grupos com as mães dos recém-nascidos internados na Unidade de Terapia Intensiva Neonatal (UTIN) e com gestantes, puérperas e acompanhantes as quais permaneciam na enfermaria. Além disso, foram feitas intervenções com os funcionários do setor, visando a discussão dos processos de trabalho e a promoção do autocuidado, considerando que o hospital vinha realizando mudanças para se adequar às diretrizes da Rede Cegonha. Foram propostas ações sem grande interferência na rotina de trabalho, mas que estimulassem a constituição de um ambiente saudável e de maior interação entre a equipe.

No âmbito da nutrição, realizaram-se atividades já estabelecidas pela nutricionista responsável pela unidade, além de outras ações necessárias na rotina diária identificadas pela equipe de residentes. Foram feitas visitas à beira do leito para adaptação da dieta, considerando as condições clínicas, como doenças/sintomas, intolerâncias e preferências alimentares das gestantes e puérperas etc. Ações individuais ou em grupo foram utilizadas para orientar a respeito do aleitamento materno e da pega correta, da alimentação na gestação, do puerpério e da lactação. Também foram realizadas avaliações nutricionais de gestantes e orientações sobre o consumo alimentar para a alta hospitalar naquelas com necessidade de restrição devido a alguma patologia.

\section{Saúde da criança}

$\mathrm{O}$ atendimento na linha de cuidado de saúde da criança foi realizado em uma unidade de internação a qual atendia desde crianças recém-nascidas até jovens com 14 anos, 11 meses 
e 29 dias. Os pacientes permaneciam internados acompanhados por seus responsáveis. A seleção das crianças seguiu a indicação dos profissionais da unidade e as demandas identificadas nos atendimentos específicos, abrangendo somente aqueles pertencentes ao território da UBS da região do Centro.

As ações da equipe de residentes multiprofissionais foram atendimentos individualizados e/ou compartilhados. Sempre que possível, houve reuniões com os profissionais da unidade de internação para discutir os casos. A equipe de residentes buscou articulação com a rede de cuidados, além de realizar atividades na sala de conforto dos acompanhantes da UTI Pediátrica. Foram realizadas oficinas de brinquedos com materiais recicláveis, práticas corporais com os acompanhantes, além de uma ação pontual de avaliação do crescimento e do desenvolvimento neuropsicomotor em crianças previamente selecionadas menores de um ano de idade.

A atuação do residente de nutrição junto à equipe da Residência foi importante e visou a conversa direta com as crianças ou responsáveis para adaptar a dieta conforme as condições clínicas observadas em prontuário e os sintomas presentes no decorrer do tratamento. Para a adaptação das dietas, foram consideradas intolerâncias e preferências alimentares das crianças de acordo com o relato dos acompanhantes ou do próprio paciente.

Nessa unidade de internação, também houve a necessidade de fazer orientações sobre aleitamento materno, pega correta e alimentação complementar. O estado nutricional das crianças foi identificado por meio das avaliações nutricionais e, depois do diagnóstico, verificou-se a necessidade de intervir nutricionalmente e monitorar, durante a internação, a aceitação da dieta e evolução do estado nutricional.

\section{CONSIDERAÇÕ ES FINAIS}

A possibilidade da atuação multiprofissional para o nutricionista é enriquecedora. O processo de compartilhar os saberes e a troca das especificidades amplia o olhar de cada profissional e resulta no objetivo comum e central do cuidado integral ao paciente.

A busca pela clínica ampliada, a multiprofissionalidade e a interdisciplinaridade vivenciadas no dia a dia da atenção básica e no ambiente hospitalar permitiram aos residentes reconhecer a importância fundamental da atuação de cada profissão ao juntar os saberes específicos para a melhor condução/intervenção. Além disso, foi importante perceber o quanto é imprescindível o (re)conhecimento do histórico de vida de cada paciente para melhor intervenção e adesão ao cuidado proposto. Assim, a intensa carga horária, a diversidade de cenários e a complexidade das situações proporcionadas pela Residência preparam o profissional para os desafios de sua futura atuação no SUS.

\section{COLABORADORES}

CC ALVES participou na redação e revisão crítica relevante do conteúdo intelectual da redação do artigo e aprovação final da versão a ser publicada. MC NETTO e APG SOUSA colaboraram na redação do artigo. MU DEVINCENZI participou na redação e revisão crítica relevante do conteúdo intelectual da redação do artigo e aprovação final da versão a ser publicada.

\section{REFERÊ NCIAS}

1. Brasil. Ministério da Saúde. Residência Multiprofissional em Saúde: experiências, avanços e desafios. Brasília: Ministério da Saúde; 2006.

2. Brasil. Presidência da República. Lei $n^{\circ} 11.129$, de 30 de junho de 2005. Institui o Programa Nacional de Inclusão de Jovens - ProJovem; cria o Conselho Nacional da Juventude - CNJ e a Secretaria Nacional de Juventude. Diário Oficial da União. 2005; 30 jun, p.1.

3. Brasil. Ministério da Educação. Resolução $n^{\circ} 3$, de 4 de maio de 2010. Dispõe sobre a organização e a carga horária dos programas de Residência Multiprofissional em Saúde e em Residência em Área Profissional da Saúde e sobre a avaliação e a frequência dos profissionais da saúde residentes. Diário Oficial da União. 2010; 5 maio, p.14. 
4. Santos IG, Batista NA, Devincenzi MU. Residência Multiprofissional em Saúde da Família: concepção de profissionais de saúde sobre a atuação do nutricionista. Interface. 2015; 19(53). http://dx.doi.org/ 10.1590/1807-57622014.0330

5. Aguiar CB, Costa NMSC. Formação e atuação de nutricionistas dos Núcleos de Apoio à Saúde da Família. Rev Nutr. 2015; 28(2):207-16. http://dx. doi.org/10.1590/1415-52732015000200009

6. Perego MG, Devincenzi MU. A gestação de um trabalho em grupo no contexto da Residência Multiprofissional. In: Pereira EMA, organizador. Inovações curriculares: experiências no ensino superior com foco na interdisciplinaridade. Campinas: Unicamp; 2014. v.1, p.863-901. Disponível em: http://www2.ea2.unicamp.br/ea2/inovacoes/ documentos/anais/2014.pdf

7. Brasil. Ministério da Saúde. Política Nacional de Atenção Básica. Brasília: Ministério da Saúde; 2012.

8. Brasil. Ministério da Saúde. Política Nacional de Humanização da Atenção e Gestão do SUS: clínica ampliada e compartilhada. Brasília: Ministério da Saúde; 2009.
9. Brasil. Ministério da Saúde. Clinica ampliada, equipe de referencia e projeto terapêutico singular. Textos Básicos de Saúde. Brasília: Ministério da Saúde; 2008.

10. Campos GWS, Domitti AC. Apoio matricial e equipe de referência: uma metodologia para gestão do trabalho interdisciplinar em saúde. Cad Saúde Pública. 2007; 23(2):399-407.

11. Brasil. Ministério da Saúde. Portaria n 1.600, de 7 de julho de 2011. Reformula a Política Nacional de Atenção às Urgências e institui a Rede de Atenção às Urgências no Sistema Único de Saúde (SUS). Diário Oficial da União. 2011; 8 jul, p.69.

12 Brasil. Ministério da Saúde. Portaria n 1.267 de 20 de junho de 2012. Aprova a etapa II do Plano de Ação da Rede de Atenção às Urgências do Estado de São Paulo e municípios, e aloca recursos financeiros para sua implantação. Diário Oficial da União. 2012; 21 jun, p.25.

Recebido: julho 7, 2015

Versão final: fevereiro 3, 2016 Aprovado: fevereiro 22, 2016 